\title{
DERECHO, MANIPULACIÓN CLIMÁTICA MEDIANTE TÉCNICAS DE GEOINGENIERÍA Y OBJETIVO 13 DEL DESARROLLO SOSTENIBLE, LA ACCIÓN POR EL CLIMA. LA VOZ QUE CLAMA EN EL DESIERTO
}

\section{LAW, CLIMATE MANIPULATION THROUGH GEOENGINEERING TECHNIQUES AND OBJECTIVE 13 OF SUSTAINABLE DEVELOPMENT, ACTION FOR THE CLIMATE. THE VOICE THAT CALLS IN THE DESERT}

María Méndez Rocasolano*

Gracias en fin, a la hermana madre Tierra que nos acoge.
Que nos da la vida y nos sostiene. Gracias por su infinita paciencia

(FRANCISCO, 2015, p. 1).

\begin{abstract}
1 Prenotandos. 2 Significado y alcance de la manipulación climática mediante técnicas de geoingeniería. 3 Aproximación a la regulación de la manipulación climática. 4 Fundamentos del derecho al clima: axiologia climática, y objetivo 13 del desarrollo sostenible, la acción por el clima. 5 Conclusiones. Referencias.
\end{abstract}

\section{RESUMEN}

La manipulación climática mediante técnicas de Geoingeniería es una realidad controvertida, escasamente regulada, necesitada de atención por parte de las instituciones, y de reflexión jurídica por las importantes consecuencias y efectos que su aplicación supone. El dominio del clima representa un poder fáctico con implicaciones económicas, sociales y culturales que, salvo bajo el ejercicio limitado por el Derecho y los Derechos Humanos, supone un riesgo real para el desarrollo de la humanidad en términos de igualdad y libertad. Tras revisar el contenido de las estrategias y normativa ambiental, en el ámbito internacional, europeo y en España, se pone de manifiesto que los valores y los principios son elementos esenciales para el logro de la garantía protección y promoción de los recursos naturales y el medio ambiente. A fin de dar cumplimiento al Objetivo 13 del Desarrollo Sostenible debe recuperarse la condición promotora e inspiradora de la regulación en materia ambiental, en la que una axiología del cambio climático, se manifiesta como elemento vertebrador del conocimiento multidisciplinar

* Doutorado em Direito pela Universidad Complutense de Madrid. Professora da Universidad Católica San Antonio de Murcia, Espanha. E-mail: <mmrocasolano@ucam.edu>. http://orcid.org/0000-0002-5345-8352 
e instrumental para el desarrollo de la conciencia ecológica y por ende la defensa y protección de los derechos humanos vinculados con el medio ambiente.

Palabras clave: Cambio Climático. Derechos Humanos. Manipulación climática. Geoingeniería. Dinamogénesis de los valores. Dinamogénesis de los derechos. Objetivos de Desarrollo Sostenible.

\begin{abstract}
Climate manipulation through Geoengineering techniques is a controversial, scarcely regulated reality, which needs attention from the institutions, and legal reflection due to the important consequences and effects implied by its application. The domain of climate represents a factual power with economic, social and cultural implications that, except under the limited exercise of Law and Human Rights, poses a real risk to the development of humanity in terms of equality and freedom. After reviewing the content of environmental strategies and regulations, at the international, European and Spanish levels, it is clear that values and principles are essential elements for achieving the guarantee of protection and promotion of natural resources and the environment. In order to comply with Objective 13 of Sustainable Development, it must recover its promoting and inspiring status in environmental regulation, in which an axiology of climate change manifests itself as the backbone of multidisciplinary and instrumental knowledge for the development of an ecological consciousness and therefore the defense and protection of human rights linked to the environment.
\end{abstract}

Keywords: Climate Change. Human Rights. Climate Manipulation. Geoengineering. Dinamogenesis of Values. Dinamogenesis of Rights. Sustainable Development Goals.

\title{
1 PRENOTANDOS
}

La intención de estas reflexiones que surgen de la investigación dentro de la línea Derecho ambiental , Economía Circular y Desarrollo Sostenible en la Universidad Católica San Antonio de Murcia es la de poner de manifiesto una realidad controvertida, escasamente regulada y necesitada de atención por parte del legislador. Aparecen desde el diálogo intelectual entre la visión práctica y el examen detenido de los hechos que aporta Victoria De Las Heras ${ }^{1}$ y las consideraciones doctrinales de la profesora Méndez Rocasolano, que planteando el derecho

$1 \quad M^{a}$ Pilar Victoria de las Heras , abogada ambientalista. E-Mail: pilarvic.heras@gmail.com .Realizó un estudio profundo de las técnicas de geoingeniería en su trabajo final de grado dirigido por la profesora Méndez Rocasolano. En el presente artículo se recogen muchas de sus aportaciones técnicas, razón por la que se presenta como un diálogo entre las dos autoras.Puede consultarse en el Departamento de Derecho UCAM "Manipulación climática mediante técnicas de geongeniería. Murcia 2017. inédito . 
al clima dentro de los posibles nuevos derechos humanos, vuelve a recuperar su conocida dinamogénesis de los valores para articular jurídicamente una posible limitación del poder a favor de la protección ambiental centrada en el cambio climático.

Por un lado, se trata de examinar la necesidad de un marco legal que regule, permita, delimite o favorezca las técnicas de geoingeniería para la manipulación del Clima. Por otro, se acentúa el desconocimiento generalizado que tiene la población y las consecuencias que a corto, medio y largo plazo representa. A continuación trataremos las evidencias científicas sobre el uso y efectos de las técnicas de geoingeniería y revisaremos la normativa aplicable junto con la necesidad de concretar jurídicamente la defensa y cumplimiento del derecho al clima como una arista del poliédrico derecho al medio ambiente adecuado para el desarrollo de la persona. ${ }^{2}$ Entendido con (MENDEZ ROCASOLANO, 2005, p. 14) como "aquello circundante al hombre, constituido y condicionado por factores químico-físico-bióticos que hacen posible una vida digna, que garantice el desenvolvimiento libre y pleno de la persona (entorno vital)"3. Al vincular al medio con derechos de la personalidad como la vida, la salud y la integridad física se contribuye al desarrollo de la persona y sobre todo a su dignidad, manifestándose aquí el carácter fundamental de este derecho. Así lo exigirá en breve la realidad, cumpliéndose lo que ya vengo anunciando hace más de veinte años. ${ }^{4}$ La relación entre la persona y ambiente en términos de dignidad equivale al desarrollo sostenible de la humanidad y al respeto y protección de la Naturaleza. En este sentido, Puy apunta que

El derecho al medio ambiente es el derecho fundamental que tiene todo ser humano a disfrutar, conservar, defender y restaurar el ecosistema físico-químico, natural y artificial en que vive, en el marco de las constantes objetivas que posibilitan el desarrollo óptimo de la vida superior e inferior (animal y vegetal), por su estabilidad a corto plazo y su persistencia para las generaciones sucesivas; y a contar con la solidaridad colectiva de los individuos y grupos sociales intermedios, en orden a la utilización racional de todos los recursos naturales, y en orden a la sanción administrativa, o el castigo penal y a la reparación civil de los deterioros causados en dicho ecosistema (PUY, 1983, p. 57).

La acción humana en los ciclos vitales del Planeta a través de las técnicas de manipulación climática altera los procesos geofísicos y geoquímicos que mantienen el equilibrio natural, en fin la vida tal y como la conocemos. Esta irrupción en la naturaleza representa un poder que en otras épocas era propio de los dioses, recordemos aquí el largo camino re-

2 Hay una manifiesta vinculación entre los derechos de la personalidad como la vida, la salud y la integridad física y en medio ambiente. En este sentido se manifiesta de forma pionera Martin Mateo (1991, p. 148). También Bellver Capella (1994, p. 231-241).

3 Es decir el aire, agua, suelo, seres vivos y las especiales condiciones cuantitativas y cualitativas necesarias para mantener el equilibrio ecológico de la biosfera y posibilitar una vida digna en la que se garantice libre y plenamente el desarrollo de la persona.

4 Para mayor abundamiento sobre el tema pueden consultarse desde la tesis doctoral del Dra Méndez Rocasolano en el repositorio de la Universidad Complutense de Madrid del año 1999 hasta sus publicaciones más recientes. Véase cristorico.juridicas.unam.mx/publica/librev/rev/trcons/cont/5/inf/inf23.pdf y https:/lucam. academia.edu/mariamrocasolano acceso 1 julio 2019. 
corrido para que las sociedades se desarrollen por la voluntad, pretensiones y herramientas democráticas a través de los Estados de Derecho, y no las de un poder o poderes de unos pocos. La vía jurídica resulta útil para el logro de tales objetivos, en palabras de Recasens (1981), el Derecho traba hecho, norma y valor, regulando la conducta humana en sociedad a partir de postulados de Justicia como hubiera dicho mi maestro Lucas Verdu. ${ }^{5}$ El uso pues de la geoingeniería para la manipulación climática dentro de los parámetros de respeto por la norma y el derecho justo, exige el reconocimiento de los valores ambientales que a través de normas e instituciones que limiten su funcionamiento al servicio de la dignidad de la persona, con los Derechos Humanos y la Democracia como referentes, la libertad e igualdad al servicio del bien común y el desarrollo, en concreto el cumplimiento de la acción por el Clima, objetivo número trece del desarrollo Sostenible como planteamos a continuación. ${ }^{6}$

\section{SIGNIFICADO Y ALCANCE DE LA MANIPULACIÓN CLIMÁTICA ME- DIANTE TÉCNICAS DE GEOINGENIERÍA}

El abordaje jurídico de cualquier tema requiere una aproximación terminológica y conceptual que fije un espacio de seguridad significativa y precisión. Más aun cuando como en el caso de la manipulación climática presenta una complejidad técnica por el significado propio de la Geoingeniería ${ }^{7}$ y un perfil claramente axiológico. En este sentido su contenido valorativo, tanto desde la perspectiva económica, como ecológica, lo configura como una alternativa al calentamiento global cuyos controvertidos efectos secundarios llevan a científicos y juristas a plantarse análisis de oportunidad y resultados en su utilización. ${ }^{8}$

De los múltiples significados que la geoingeniería comporta, interesa aquí el que mantiene el Panel Intergubernamental de Expertos sobre Cambio Climático, por el que entiende el "vasto conjunto de métodos y tecnologías que tiene por objeto alterar deliberadamente

5 Para Recasens "El derecho es un hecho, una obra humana, estimulada por la conciencia de unas necesidades en la vida social, obra producida bajo la forma normativa; y que en su función para satisfacer esas necesiades intenta hacerlo de acuerdo con la realización de unos valores específicos." (RECASENS SICHES, 1981, p. 40). Aconsejo también la consulta de la Teoría tridimensional de Reale (1968) y la obra de Lucas Verdú referenciada entre 1957 y 2018 en https://dialnet.unirioja.es/servlet/autor?codigo=49663.

6 Aquí sólo se dibuja esta propuesta, que está siendo más ampliamente desarrollada por la Doctora Mendez Rocasolano que verá la luz como continuación del presente artículo.

7 La escala y el propósito tienen una importancia fundamental. Dos de las principales características de los métodos de geoingeniería de especial interés son los que, o bien emplea el sistema climático o tienen efectos sobre él (por ejemplo en la atmósfera, la tierra o el océano) a nivel global o regional La mayoría de los métodos utilizados, si bien no todos ellos, tratan de:1) reducir la cantidad de energía solar absorbida en el sistema climático (gestión de la radiación solar) 2) aumentar los sumideros netos de carbono procedente de la atmósfera a una escala suficientemente grande para alterar el clima (remoción del dióxido de carbono). Vease aquí VVAA, Grupo Intergubernamental de Expertos sobre el cambio climático (2014, p. 195.)

8 Ha de tenerse en cuenta que en el cambio climático además de las causas de origen antropogénico se encuentran los propios ciclos de la Tierra, como las interglaciaciones, períodos de tiempo entre glaciaciones caracterizados por un clima anormalmente cálido en comparación a la media y subida del nivel del mar. 
el sistema climático a fin de aliviar los impactos del cambio climático" (STOCKER et al., 2014, p. 16). Esta definición no parece que sea la que guía hasta aquí su uso, como pone de manifiesto el impulsó militar y económico con el que se han desarrollaron tales técnicas. ${ }^{9}$ Destaca aquí el concepto de la Convención sobre la Prohibición de utilizar técnicas de modificación ambiental con fines militares u otros fines hostiles, aprobada en la Asamblea de las Naciones Unidas el 10 de diciembre de 1976 que en su artículo II, entiende que son las que tienen por objeto cambiar, con la alteración intencionada de los ciclos naturales, la dinámica, constitución o composición de la Tierra, incluyendo la biosfera, litosfera, hidrosfera, atmósfera y el espacio ultraterrestre. ${ }^{10}$

Hasta la fecha se ha asumido la modificación climática como elemento de control y poder, vinculándose principalmente al ámbito de la Seguridad y Defensa. En nuestros días como hemos indicado líneas arriba se considera una de las vías posibles para la lucha contra el cambio climático. En cualquier caso, la acumulación de una acción tan poderosa como la que posibilita el cambio climático, implica riesgos. Por ello no es extraño que la Convención ENMOD aprobada por la Asamblea General de Naciones Unidas, estableciese la prohibición de utilizar técnicas de modificación ambiental con fines militares u otros de carácter hostil..1

Aparecen en escena además los peligros en relación con el abuso del poder que estas técnicas pueden representar. El tratamiento del poder y sus manifestaciones ha guiado todo el derecho político que desde Montesquieu hasta nuestros días establece la teoría de la división del poder y la necesaria titularidad colectiva de la sociedad y las personas que la conforman, algunas de sus consideraciones se actualizan con el tema que nos ocupa. Es interesante en este punto la desafección de contenido con la que éste concepto ha sido trasladado a la sociedad civil, teniendo en cuenta que los métodos de control del clima de manera artificial están al servicio de los intereses estratégicos de índole militar, económica, social y por supuesto gu-

9 De hecho, son numerosos los antecedentes de la manipulación climática basada fundamentalmente en intereses estratégicos militares .Así se expresa el informe El clima como multiplicador de fuerza: poseyendo el clima en 2025. Como ejemplo mencionemos las precipitaciones causadas en la guerra contra Vietnam aplicando técnicas de geoingeniería por parte del ejército estadounidense. Permitieron inundar y hacer impracticable la senda Ho Chi Minh, la vasta estructura de vías transitables tanto por el Vietcong como por los propios vietnamitas, que vieron de ese modo mermada su capacidad de adquirir y/o transportar suministros. Además de rociarla con el conocido como agente naranja, potente herbicida de resultados catastróficos en la salud de la población. Murphy (2013, online).

10 En la conferencia se regula la capacidad de dominio que tiene un Estado al controlar el clima, pues en resumidas cuentas viene a ser una de las formas más sencillas de ganar la guerra aun sin disparar un mísil; tan sólo creando, o modificando las condiciones atmosféricas, de modo que hagan al enemigo retroceder antes de haber dado un paso. En esta línea se expresaba a finales del siglo XX Gordon MAC DONALD "Entre los medios para lograr objetivos nacionales por la fuerza destaca el potencial del hombre para controlar y manipular el medio ambiente de su planeta." (GUARDACIELOS, 2016, p. 6).

11 ASAMBLEA GENERAL DE NACIONES UNIDAS. Resolución 31/72. Convención sobre la prohibición de utilizar técnicas de modificación ambiental con fines militares u otros fines hostiles. de 10 de diciembre de 1976. Ello supuso un freno al avance militar en la investigación de este tipo de técnicas. Sin embargo, nada hace presagiar que se abandonaran desembocando hoy en día en justificaciones de índole ambiental para su desarrollo y/o aplicación. Disponible en: http://legal.un.org/avl/pdf/ha/cpmhuemt/cpmhuemt_ph_s.pdf. Acceso: 1 jul. 2019. 
bernamental de los Estados. ${ }^{12}$ En esta materia parece que la realidad se aleja de la Teoría del Derecho Político y del Derecho Constitucional quebrándose las columnas vertebrales de los llamados Estados Democráticos de Derecho cuya esencia se "sitúa en el hecho que protege y estimula el avance de todas las fuerzas naturales, desarrollo reconocido por el pueblo como objetivo de la vida del individuo y el conjunto de la sociedad." (VON MOHL, 1872, p. 57) Acierta plenamente (FERRAJOLI, 1999) cuando insiste en que el problema consiste en no haber construido hasta ahora garantías adecuadas para la tutela de los derechos políticos y los derechos sociales ${ }^{13}$ ámbito en el que se enmarca con carácter general el medio ambiente y el derecho al Clima con carácter particular.

Ha de ocurrir pues en relación con el Clima igual que en otros casos donde el poder ha sido limitado por la potencia de la dignidad de la persona y sus derechos inialialeniables, me refiero a toda la pléyade de derechos sociales, políticos y culturales que frente al poder establecido fueron adquiriéndose desde la segunda mitad del siglo XX hasta la actualidad y que todos conocemos. iAcaso el derecho al Clima no será un heredero de las luchas contra el poder para disfrutarlo por todos en igualdad y libertad? Las declaraciones del Derechos, especialmente el Pacto de los derechos económicos sociales y culturales y los principios Limburg establecidos para su correcta interpretación y aplicación, pueden ser herramientas útiles para establecer las garantías que se precisan como veremos más adelante. Resulta imprescindible la incorporación del derecho al clima a la dialéctica de los Derechos Humanos, del Estado de derecho y de la Democracia. De otro modo habremos olvidado la Secularización, la Carta Magna, las enseñanzas de Bartolome de las Casas, de Rosseau, de la Declaración del Hombre y del Ciudadano y la de los Derechos Humanos en los cuales se reconocen derechos a los hombres en igualdad y libertad. En definitiva, a los pueblos se les reconoce el poder soberano y a los hombres su dignidad. En la actualidad en los llamados países democráticos (al menos teóricamente) la voluntad popular guía las normas e instituciones que regulan las realidades sociales, requiriendo para ello información veraz sobre las actividades de los poderes públicos y sus agentes, pues las elecciones de la ciudadanía en democracia determinan el tipo de Estado, el tipo de normas, el tipo de convivencia que un pueblo quiere para sí.

Teniendo en cuenta así, al pueblo como titular de la soberanía de los Estados, es una anomalía sistémica la ocultación de acciones que pueden afectar directamente a su vivir y a

12 En este sentido seguimos con el caso de Estados Unidos y el informe del Departamento de Defensa de la Escuela de medio ambiente y libertad académica, El Clima como multiplicador de fuerza: Poseyendo el Clima en 2025 donde a pesar de ser redactado por y para militares, cree necesario hacer llegar el conocimiento de la geoingeniería a la población civil desde una perspectiva desprovista de connotación militar alguna. Argumentando la idoneidad de su aplicación en las catástrofes a que se ve expuesta la población, asociadas a "fenómenos climatológicos inaceptables". Incluso advirtiendo la necesidad de no usar la noción "modificación climática", dada la tendencia al rechazo que pudiera suponer este término. Owning the wheather in 2025 en su título original, traducido al español por www.guardacielos.org). Col Tamzy J. Hause, Lt Col William B. Shields (USA), Maj Ronald J. Calentano et al. 1996 Disponible en: http://www.guardacielos.org/users/1/Documentacion/Poseyendo_el_clima_en_2025. pdf. Acceso: 12 jul. 2019.

13 (FERRAJOLI, 1999, p. 17). 
su devenir. Esto ocurre con el caso que nos ocupa, durante décadas se ha negado desde las instituciones y desde el campo científico la utilización de las técnicas de manipulación del clima incorporándose al relato de la conspiración y por ende vaciándolo de peso científico y de validez técnica. Si el Cambio Climático es el primer problema medioambiental, frente al que el ser humano ha de posicionarse resueltamente, aportando acciones que lo frenen, también debe conocer la humanidad qué acciones se están realizando y con qué finalidades. ${ }^{14}$

En cualquier caso, se ha de evitar el daño ecológico, que por error o ignorancia pueda causar perjuicios graves o irreversibles, estableciéndose la protección del medio ambiente como un deseo de los pueblos y una obligación de los Gobiernos. La vasta y desconocida industria de la geoingeniería, desde sus mecánicos y rudimentarios comienzos, hasta la gran industria en la que se ha erigido, controla de manera amplia y sin restricciones, las variables sobre las que estructurar el control y dominio sobre el Clima, como indicábamos al principio. En este área, el Derecho como expresión cultural y de superación de las relaciones básicas de dominio entre amos y siervos cobra protagonismo. A continuación veremos en qué consisten las técnicas de geoingeniería para la manipulación del clima y apuntaremos algunas consideraciones jurídicas en pro de un posible derecho al Clima. Este artículo y la difusión de su contenido forman parte de la necesaria concienciación sobre el asunto, paso previo, inicial y definitivo para poder hablar de la categoría, derecho de o derecho a el clima.

Detengámonos brevemente en el examen de las técnicas de Geoingeniería como métodos de mitigación del cambio climático basadas en la remoción del dióxido de carbono, CDR (Capture Dioxide Removal) y en la gestión de la radiación solar, SRM (Solar Radiation Management).

En estados Unidos, el informe del Herndon (2015) aporta pruebas fotográficas de San Diego captadas en el trayecto de los numerosos aviones que sobrevuelan la ciudad, siempre en patrones repetidos, por lo general reticulares, que se van abriendo y cubriendo el cielo de una capa blanquecina, opaca, que no permite el paso de los rayos del Sol. A partir del análisis de las partículas encontradas indica que se está aerosolizando la atmósfera con cenizas volantes de carbón. Por un lado aporta pruebas que permiten, a partir de la evidencia analítica, despejar dudas sobre su utilización real y por otro, señala las consecuencias que el aluminio, bario, estroncio y otras sustancias junto con las partículas volantes de carbón tienen en la salud del ser humano, la biodiversidad y los recursos naturales. Realiza dos comparativas. En una de ellas, se analizan ocho elementos hallados en agua de lluvia después de episodios de inyecciones de aerosoles en la troposfera, lixiviados de partículas aerosolizadas, con los correspondientes elementos lixiviados en agua de cenizas volantes de carbón. En la otra analiza catorce elementos hallados en polvo recogido del exterior con filtros HEPA ${ }^{15}$

14 La Convención Marco de la Naciones Unidas Sobre el Cambio Climático, Nueva York 1992, conocida también por sus siglas CMNUCC establece el Cambio Climático en su artículo 1, como el "...cambio del clima atribuido directa o indirectamente a la actividad humana que altera la composición de la atmósfera global y que se suma a la variabilidad natural del clima observada durante periodos de tiempo comparables". (NACIONES UNIDAS, 1992, p. 3).

15 Filtros HEPA del inglés High Efficiency Particulate Air, adquiridos de la empresa Honeywell, Arizona. 
frente a los elementos correspondientes analizados en material de cenizas volantes de carbón no lixiviado concluyendo de igual forma. ${ }^{16}$ Este hecho no es aislado, dándose en múltiples localidades norteamericanas, igual que en Europa, donde también se han llevado a cabo análisis de las partículas en el agua de lluvia después de episodios de inyección de aerosoles en la atmósfera. Los resultados parecen concluyentes indicando que se están produciendo inyecciones de aerosoles, además las composiciones similares halladas en los análisis, suponen una demostración añadida. ${ }^{17}$

Arrojar sustancias a la atmósfera a través de procesos de inmisión o emisión contaminante es ilegal y constituye delito ambiental, entonces porqué se están proyectando estas partículas en la troposfera, cuando costó mucho que se regulara su uso, recogida y almacenamiento. ${ }^{18}$ El hecho de que las fumigaciones se realicen en la troposfera, la capa más cercana a la Tierra, implica peligros a la salud y el medio ambiente a través de un rápido descenso de las partículas, lo que el grupo de expertos sobre el cambio climático expresa como uno de los retos especiales que surgen de las instituciones y los mecanismos internacionales que podrían coordinar la investigación y posiblemente controlar las pruebas y su implantación ${ }^{19}$. Al hablar de los componentes de las cenizas, se ha citado el aluminio, el bario y el estroncio, como elementos básicos. También se advierte la presencia de arsénico, berilio, boro, cadmio, cromo III y IV, cobalto, plomo, manganeso, mercurio, selenio, talio, torio y uranio entre otras. La acumulación e interrelación química de estas sustancias aumenta su toxicidad desencadenado un importante catálogo de enfermedades que afecta en función de los individuos expuestos a ellos (personas mayores, infantes, mujeres embarazadas, condición física en la que se encuentre la población etc). En los lugares en los que se realizan prácticas de manipulación del clima se constata un aumento de las enfermedades degenerativas, entre las que el alzheimer muestra prevalencia, presentándose también casos de autismo, parkinson, hiperactividad, infertilidad masculina, etc. ${ }^{20}$

16 (HERNDON, 2015, p. 9375-9390.)

17 Existen evidencias en archivos periodísticos al respecto de generar lluvia de manera artificial, citando a Byers (1974). También Meyer (1986). Seguimos la remisión a Moreno et al. (2005, p. 1351-1363) Obtenido el 1 de agosto de 2019 en http://www.sciencedirect.com/science/article/pii/S0016236104003394.

18 Vease el Dictamen del Comité Económico y Social Europeo sobre el tema «El tratamiento y la explotación de los residuos industriales y mineros de la Unión Europea con fines económicos y medioambientales», 26 de octubre 2011. P16/24, apartado 6.2 pone de manifiesto el rompecabezas y el conflicto que suponen para las comunidades de la UE los productos que derivan de la combustión del carbón, entre los que figura, encabezando la nómina, las cenizas volantes de carbón. Su tratamiento es objeto de estudio, planificación y coordinación. En EEUU se creó en 1968 una Asociación que trata todos estos aspectos de gestión de los productos derivados de la combustión del carbón, conocidos como PCC. Por su parte, la Directiva Marco de Residuos 2008/98/CE establece los usos y fines de determinados residuos, entre los que se encuentran las cenizas volantes de carbón. Las cenizas volantes de carbón son liberadas en la combustión durante el proceso de la fabricación del cemento (CALLEJA, 1982, p. 3-38).

19 Grupo Intergubernamental de Expertos sobre el Cambio Climático (2014, p. 97) Para el informe completo Cfr. http://www.ipcc.ch/report/ar5/wg1/ y para las Guías resumidas del Quinto Informe de Evaluación del IPCC https://www.miteco.gob.es/es/ceneam/recursos/mini-portales-tematicos/Cclimatico/informe_ipcc. aspx. Acceso en: 5 jul. 2019.

20 Destacan las enfermedades pulmonares, al situarse los componentes, debido a su tamaño inferiores a 2'5 PM 
Las técnicas de manipulación climática tienen también, como hemos indicado un contenido axiológico importante, pues cobran relevancia inusitada las implicaciones económicas, éticas, morales, y la repercusión que conllevaría, entre otros, el hecho de que determinados países, de manera independiente y unilateral, implementen este tipo de métodos de geoingeniería con lo que ello representa al margen de la Comunidad Internacional. Además, posee una importante trascendencia en materia de justicia intra e inter generacional. ${ }^{21}$ Es la dimensión ética, la que ha de estar más involucrada en los procesos de regulación normativa para ordenar la ley y el derecho de cada ser humano a la salud medioambiental, a la defensa de la integridad física que deriva de la salubridad del medio en que vive y se desenvuelve.

En definitiva, del método, aplicación e implementación de las técnicas de geoingeniería surgen interrogantes que deben consensuarse, buscar un diálogo ente las potencias, y entender que es una cuestión de ámbito mundial, en el que han de participar todos los países. Es una realidad que se está dando a gran escala, y de manera sistemática, mirar a otro lado es imposible.

En España, la Plataforma Cívica Guardacielos, promovida por la Asociación Terra SOS-Tenible, y al frente de ella, Josefina Fraile Martín ${ }^{22}$, es responsable de acciones encaminadas a arrojar luz sobre el desconocimiento generalizado de la población frente a la existencia de estas técnicas y las pruebas que refutan su uso. En esta dirección ha solicitado al Parlamento Europeo ${ }^{23}$, como al Congreso de los Diputados ${ }^{24}$, su implicación para investigar estas actividades en España y en Europa.

(micras) en las terminaciones y alveolos de los pulmones, donde permanecen durante largo período de tiempo. En cuanto a la biodiversidad las abejas, insectos que muestran una sensibilidad especial, están dando muestras de problemas neurológicos y no sorprenden por desgracia, las abundantes referencias a las tasas de mortalidad que en la actualidad están presentando debido a la presencia de sustancias contaminantes en la atmosfera como indicaba en el 2009 el informe Geoengineering the climate Science, governance and uncertainty https://royalsociety.org/ /media/Royal_Society_Content/policy/publications/2009/8693.pdf. Acceso 23 noviembre 2018

21 La idea de la justicia intra e inter generacional inspira el derecho que ha de regir en el orden normativo e institucional que regula la conducta humana en sociedad, basada en parámetros de desarrollo sostenible, es decir aquel capaz de favorecer el mantenimiento de las actuales generaciones sin poner en peligro el sostenimiento de las futuras. Con este referente se plantean los interrogantes de la capacidad de conservación de la biodiversidad o la disponibilidad del agua en una eventual implantación y/o la implementación de estas técnicas. Se ponen de relieve la distribución de ingresos, la eficiencia del sistema tributario, ofertas de empleo, o la expansión urbana y el tipo de ciudades. En este último sentido recomiendo la lectura de Mendez Rocasolano (2017).

22 Para saber más de esta Plataforma, sus acciones de información y reivindicaciones, visitar la Página Web www.guardacielos.org.

23 Josefina Fraile es promotora de una petición al Parlamento Europeo, junto a Giulietto Chiesa (periodista y político italiano, elegido eurodiputado en 2004), en base al artículo 227 TFUE (derecho de petición) para que se investiguen y pongan de manifiesto las actividades de geoingeniería que se están llevando a cabo en toda Europa. Esta Petición (no 0964/2013) fue admitida a trámite en marzo de 2014. Actualmente, y tras una respuesta demorada por más de dos años del Parlamento Europeo, aludiendo a la falta de competencia del Parlamento por pertenecer el asunto al ámbito militar, se ha presentado recurso al archivo de la misma en base a esta Opinión de la Comisión Europea, la cual fue formulada el 29 de abril de 2016. El recurso puede consultarse en la página http://www. guardacielos.org/users/1/Documentacion/Recurs_Archivo_Peticion_Parlamento_Europeo_ESP.pdf. 


\section{APROXIMACIÓN A LA REGULACIÓN DE LA MANIPULACIÓN CLI- MÁTICA}

En el ámbito del derecho nacional la legislación pionera y más desarrollada es la National Weather Modification Policy Act relativa a la modificación climática. ${ }^{25}$ En 1976, el Congreso norteamericano promulgó esta Ley, partiendo de la existencia de fenómenos meteorológicos adversos como tifones, tormentas, pedrisco, relámpagos, neblina, torrentes y heladas. En relación con el impacto negativo que producen, planteaba la modificación climática como una herramienta eficaz para su prevención, restando importancia a los efectos desfavorables que pudieran ocasionar tales usos. Igualmente, al respecto de la disponibilidad sobre el agua y la mejora de la productividad asociada a la misma. En este sentido dibujamos aquí la importancia de influir sobre las precipitaciones, lo que supone una actuación sobre el ciclo el agua y la afección, por lo tanto del nuevo Derecho Humano incluido en la Declaración Universal que el derecho al agua representa. ${ }^{26}$ Aquí hablamos de palabras mayores. La ley designa al Gobierno Federal como el máximo responsable de aliviar y prevenir los males derivados de las inclemencias metereológicas, procediendo a una regulación en pro de una política de modificación del clima que se viene desarrollando a través de programas nacionales de modificación del tiempo atmosférico. ${ }^{27} \mathrm{Es}$, en definitiva, una ley que abiertamente reconoce la capacidad de manipulación humana del clima al servicio del desarrollo económico, con la intención de evitar las pérdidas ocasionadas por los fenómenos meteorológicos que no sin razón se denominan "devastadores". No se trata de juzgar o analizar en estas líneas el componente ético de esta norma, sino el elemento objetivo que nos permite reconocer la existencia de un avance tecnológico capaz de ser aplicado en el control del clima, frente a la generalizada falta de reconocimiento legislativo de tales asuntos en el resto de países. En definitiva, esta norma es una muestra concreta de la capacidad del ser humano para crear condiciones que le resulten favorables y legislar en ese sentido, adaptando la realidad a su conveniencia. ${ }^{28}$

Si bien la legislación norteamericana ha dado forma a una posible regulación de la manipulación humana del Clima, es en el ámbito del Derecho ambiental internacional donde tiene pleno sentido. Así resulta obligado recordar que

25 National Weather Modificaction Policy Act of 1976, Septiembre de 1976, EEUU. Obtenido el día 17 de agosto de 2016 en https://www.govtrack.us/congress/bill s/94/s3383/text.

26 Recuérdese que el 28 de julio de 2010, mediante la Resolución 64/292, la Asamblea General de las Naciones Unidas reconoció explícitamente el Derecho Humano al Agua y al Saneamiento, reafirmando que un agua potable limpia y el saneamiento son esenciales para la realización de todos los derechos humanos. La Resolución exhorta a los Estados y organizaciones internacionales a proporcionar recursos financieros, a propiciar la capacitación y la transferencia de tecnología para ayudar a los países, en particular a los países en vías de desarrollo, a proporcionar un suministro de agua potable y saneamiento saludable, limpio, accesible y asequible para todos.

27 Es interesante subrayar el término "modificación del tiempo" como cualquier actividad con la intención y la expectativa de producir cambios en las precipitaciones, y demás fenómenos metereológicos

28 Desde el 2018 el presidente TRUMP ha implementado técnicas de geoingeniería recordemos que EEUU bajo su presidencia ha salido del Acuerdo de Paris 
El derecho de la humanidad a un medio ambiente sano y equilibrado es indisociable de los otros derechos y particularmente del derecho a la vida, a la dignidad, a la libertad, a la igualdad, a la democracia, a la paz y a la justicia; y...de que el derecho de la humanidad al medio ambiente debe ser democrático, justo y pacífico. (UICN Resolución 6081, 2016, p. 2).

Por su naturaleza, técnica, trasnacional y poderosa requiere la unidad indiscutible de todas las naciones al respecto de su uso. Una panorámica sobre legislación internacional respecto al clima nos lleva al Protocolo de Kioto (1997), adicionado a la Convención Marco de las Naciones Unidas sobre el Cambio Climático. Si bien se incorporaron nuevas medidas con carácter jurídicamente vinculantes, después de múltiples revisiones como la de Nairobi 2006 o Cancun en el 2010 es en Paris 2015 cuando se expresa con claridad el objetivo de estabilizar las concentraciones de gases de efecto invernadero en un plazo que posibilite la adaptación natural de los ecosistemas al cambio climático. Anualmente en las Conferencias de los Estados Parte se ha buscado lograr su finalidad, siendo en la de Katowice del 2018 en la que se ha tratado el establecimiento de un Libro de Reglas, es decir el marco técnico para poner en marcha el Acuerdo de París. Durante el 2019 se han establecido mecanismos de cooperación, se ha comenzado a trabajar sobre las normas que han de tenerse en cuenta para la realización del diagnóstico global proyectado para el 2023 y el nuevo objetivo de financiación climática global del 2025. También se han aprobado medidas para mejorar la información y las actuaciones de adaptación al cambio climático, creándose el Comité de Cumplimiento del Acuerdo de París y las declaraciones sobre transición justa, movilidad eléctrica y bosques. ${ }^{29}$

Precursora de la visión transformada del hombre hacia el medio que le rodea, punto de inflexión a partir del cual se comienza a legislar teniendo en cuenta la necesidad de protección que ha de primar sobre otros intereses, la Conferencia de Naciones Unidas sobre el Medio Humano, celebrado en Estocolmo del 5 al 16 de junio de 1972, supuso un antes y un después en la conciencia ecológica. A través de sus Principios y Recomendaciones ${ }^{30}$, se ha trazado el camino de la normativa y las políticas de protección y prevención, referentes básicos para la acción en defensa del medio ambiente que ahora recuperamos.

El derecho ambiental internacional nace de la imperiosa exigencia de evitar daños inmensos e irreparables a los ecosistemas, sus recursos y seres vivos de los que dependen nuestra vida y bienestar. ${ }^{31}$ Respecto a la descarga de sustancias tóxicas, expresa la obligación de estar pendientes de las condiciones o circunstancias que pudieran dañar el medio, en el cumplimiento de la solemne obligación de proteger y mejorar el medio ambiente para las generaciones presentes y futuras, destacando la protección de los recursos naturales, el aire,

29 Véase https:/unfccc.int/process-and-meetings/conferences/katowice-climate-change-conference-december-2018/katowice-climate-change-conference-december-2018 Consultado el 3 de junio de 2019. La próxima cumbre será en Chile para mayor información https://sdg.iisd.org/events/unfccc-cop-25/

30 Téngase en cuenta la referencia a principios se indica en el texto como pertenecientes a la Conferencia de Estocolmo por no hacer redundante la continua referencia a los mismos.

31 Así lo establece el número 3 de la Conferencia de Naciones Unidas sobre el Medio Humano. 
el agua, la tierra, la flora y la fauna. ${ }^{32}$ Parece que la utilización de cenizas volante de carbón y el resto de componentes que les acompañan no está dentro de lo admisible, más aun si tenemos en cuenta su carácter transfronterizo. En este sentido el Principio n ${ }^{\circ} 21$ alerta de la obligación que han de tener los Estados, dentro de la libertad que tengan para aplicar sus políticas ambientales, de cuidar que las acciones desarrolladas bajo su jurisdicción, no perjudiquen a otros Estados. En concreto, en el Capítulo II, titulado Plan de Acción para el Medio Humano, se llama a los Estados a la procura efectiva de conocimientos para poder mediar las fuentes, trayectorias, niveles de exposición y riesgos relativos a los agentes contaminantes. ${ }^{33}$ Especialmente se refiere a la capacidad que tiene los Estados para prever los efectos perjudiciales que los contaminantes tiene sobre el ser humano y su bienestar ${ }^{34}$ y se hace hincapié respecto de los potenciales peligros por riesgo de mutagenicidad, teratogenicidad y cancerigenidad, provocados por los contaminantes ambientales. De igual forma se recomienda inspeccionar los niveles de contaminación química y/o biológica de los alimentos y vigilar la composición atmosférica mundial mediante estaciones estratégicamente ubicadas. ${ }^{35}$ En definitiva, hay una supervisión, incluso Programas creados al efecto, tipo GARP ${ }^{36}$ para comprender la dinámica atmosférica, y ayudar a determinar las causas de los cambios climáticos, ya sean de origen natural o antropogénico. ${ }^{37}$ Con ello se establece un control y mecanismos de vigilancia de la acumulación de componentes peligrosos en materias biológicas y abióticas en especial contaminantes que sean comunes al agua, al aire, y a los alimentos con la intención de establecer parámetros cuantitativos de seguridad ${ }^{38}$ esto parece que se desconoce cuando se desarrollan las técnicas anteriormente mencionadas.

A partir de estos Principios y Recomendaciones, recordemos todavía vigentes, se ha construido la infraestructura jurídico política que sostiene los pilares de la protección ambiental. En lo que respecta a la atmósfera a través del intricado despliegue de criterios, parámetros y acciones del Protocolo de Kioto hasta el Acuerdo de París propone medidas de protección y cuidado del Clima terrestre. Especial consideración aquí tienen los gases efecto invernadero, los créditos de carbono y el impulso de la economía circular a través de normas y estrategias para su implementación. ${ }^{39}$ A pesar de los importantes esfuerzos que la

32 Principios 2, 6, y 18 de la Conferencia de Naciones Unidas sobre el Medio Humano.

33 Véase "Recomendaciones", y ya dentro del Apartado "Contaminación en General", la recomendación 73.

34 De acuerdo a la Recomendación 74 a).

35 Véanse la recomendación 76 y 78 de la Conferencia de Naciones Unidas sobre el Medio Humano.

36 Programa Mundial de Investigación Atmosférica.

37 Programa sobre el Hombre y la Biosfera, MAB por sus siglas en inglés, puesto en marcha a comienzos de la década de los 70 por la UNESCO. Su objetivo es mejorar la relación entre el hombre y el medio que le rodea.

38 Recomendaciones 79 a 83.

39 En el ámbito europeo especialmente destacan el régimen europeo de comercio de derechos de emisión a través de la Decisión no 377/2013/UE del Parlamento Europeo y del Consejo de 24 de abril de 2013 que establece una excepción temporal a la Directiva 2003/87/CE por la que se establece un régimen para el comercio de derechos de emisión de gases de efecto invernadero en la Comunidad y Marco sobre clima y energía para 2030 . Los objetivos fundamentales del marco de clima y energía para 2030 en primer lugar su- 
comunidad internacional está desarrollando parece que no están siendo efectivas, pues ya hemos superado las 400 partes por millón de CO2, lo que en términos científicos es equivalente al "punto de no retorno". Esto lleva a instituciones tan relevantes como la NASA a indicar que entramos en un territorio desconocido para la raza humana. ${ }^{40}$

Con los anteriores referentes llama la atención que no exista una regulación concreta sobre la cuestión de la geoingeniería que recoja abiertamente las cuestiones relativas a las técnicas de modificación climática. Tanto en el Panel Intergubernamental de Expertos sobre el Cambio Climático, como destacados informes como el de la Royal Society, entre otros, plantean estas técnicas, a pesar de incertidumbres en relación con la biodiversidad y la gobernanza. Si estos métodos se proyectan como un remedio eficaz, o alternativa viable, ¿por qué no se regula eficazmente su aplicación? La contestación radica en que además de las bondades que pudiera suponer al respecto del cambio climático, y la economía, suponen la proyección de materiales nocivos a la troposfera. Si no se avanza en ese camino, de nada servirán las Conferencias, Acuerdos y Protocolos, que reconocen la responsabilidad antropogénica ante el cambio climático y la protección ambiental. Serán equivalentes a un esqueleto inerme sostén de ideas vacías, sin esencia, sin telos, en palabras del Papa Francisco sin los esfuerzos puestos al servicio del fin último que la protección de la casa común representa (FRANCISCO, 2015).

Como hemos visto la Conferencia estima la idoneidad de que los Estados tengan y fomenten los conocimientos que permitan tanto la previsión de los posibles daños, como el seguimiento de planes y programas de evaluación de riesgos de acumulación de determinadas sustancias en la atmósfera. Así pues un mecanismo legislativo que realmente analice la estructura y composición atmosférica y ponga de manifiesto que se está emitiendo con exactitud a la atmósfera en la aplicación de éstas técnicas resulta imprescindible. Es necesario regular estas actividades, determinando cuando han de usarse, en qué condiciones, con qué requisitos y bajo que qué autorizaciones, entre sus más importantes extremos figuraría también el régimen sancionador que ha de acompañarlas.

En el Derecho ambiental internacional los criterios de cooperación y colaboración entre los Estados son imperativos. Para su correcta aplicación se precisa el intercambio y la participación, especialmente la científico-técnica pues se trata de poner a disposición las herramientas,

pone al menos $40 \%$ de reducción de las emisiones de gases de efecto invernadero (en relación con los niveles de 1990), en segundo reducir también al menos $27 \%$ de cuota de energías renovables y finalmente al menos $27 \%$ de mejora de la eficiencia energética para ello se ha desarrollado el llamado paquete de medidas sobre clima y energía hasta 2020. Vease https://ec.europa.eu/clima/policies/strategies/2030. Al respecto de la economía circular recomiendo la consulta de ttps:/ec.europa.eu/commission/publications/documents-strategy-plastics-circular-economy es donde aparece explicado el Plan de Acción para una economía circular en Europa de la Comisión Europea. También https://ec.europa.eu/clima/policies/strategies/2030_es.

40 Entre múltiples páginas informativas sobre el punto de no retorno Have We Passed the Point of No Return on Climate Change? https://www.scientificamerican.com/article/have-we-passed-the-point-of-no-return-on-climate-change/ (abril 13 2015) https://climate. nasa.gov/ climate_resources/7/ graphic-carbon-dioxide-hits-new-high/y http:// www.realclimate.org/index.php/data-sources/.Acceso agosto 2019. 
la información y el desarrollo de los mecanismos que corrijan el desastre que la economía lineal ha producido en la relación del mundo y la humanidad. El efecto transfronterizo junto con la denominada justicia inter e intrageneracional, exige la lucha y contención de desigualdades entre las naciones, para que la posibilidad de llevar a cabo estas prácticas, no dependa de su grado de desarrollo económico. Como indica el Acuerdo de Paris de forma inequívoca cada Estado ha de responsabilizarse de las actividades que generan efectos contaminantes transfronterizos como las que hemos visto para manipular el clima. Esta responsabilidad que sanciona económicamente a partir del principio de que quien contamina paga, ha puesto precio a la degradación ecológica. Llevo tiempo criticando este principio, que he entendido siempre como un error, en materia ambiental debe imperar el principio de prevención en la previsión de los daños, por el carácter en muchos casos irreparable e irreversible del daño producido. En este sentido han de revisarse los Tratados, Declaraciones y Conferencias en materia de medio ambiente, antecedentes de la Declaración del Milenio y de los actuales Objetivos del Desarrollo Sostenible. Desde el derecho a una vida saludable, hasta el equilibrio con la naturaleza que el desarrollo sostenible representa, plantean el compromiso de prohibir y prever actuaciones en esta década 2020-2030 que es la de la acción. ${ }^{41}$ Ya no son suficiente las buenas intenciones, los programas, ni los futuros compromisos con el cambio climático y con la preservación de los ecosistemas, se requiere como indicábamos líneas arriba, la ejecución de los mandatos de Derecho ambiental, la actuación de los operadores jurídicos para el necesario cambio de paradigma que demanda el cuidado del Planeta. Es preciso imprimir en la actual sociedad líquida e individualista la consciencia de la necesidad de cuidar nuestro mundo bajo la aplicación de un economía circular sobre la cual se ha de edificar el crecimiento a fin ya no de preservar sólo los intereses de las generaciones venideras, si no la vida de las presentes. La protección ambiental es un imperativo, como la vida misma, lógico, ontológico y deontológico, vinculado directamente al desarrollo que hoy se plantea desde los Objetivos del Desarrollo Sostenible y en nuestro caso con el clima.

De fundamental transcendencia para la regulación sobre el cambio climático es el mencionado acuerdo de Paris que como expresión de los múltiples esfuerzos realizados desde la comunidad científica internacional, las instituciones y los Estados firmantes (174 países y la Unión Europea). Reclama de manera imperativa su absoluto compromiso para reducir dos grados centígrados la temperatura del planeta. Para ello busca implementar políticas de reducción de emisiones carbónicas a la atmósfera y políticas de desarrollo sostenible, que abarquen todas las esferas: jurídica, educacional, económica, financiera, social, etc. Este Acuerdo se muestra como el titánico intento de aglutinar las intenciones de todos los Estados de cara a preservar la vida sobre la Tierra. Una llamada a la conciencia acomodada de las Naciones y sus ciudadanías, que parecen ajenas al drama de la degeneración ambiental. La falta de compromiso del gobierno de Estados Unidos que junto con China representan el $38 \%$ de las emisiones globales sirve de indicador. ${ }^{42}$

41 Para ella se ha creado la Agenda 2030 para el Desarrollo Sostenible que concreta los Objetivos de Desarrollo del Milenio. La Agenda define 17 objetivos y 169 metas, combinando la dimensión económica, social y ambiental para lograr un desarrollo sostenible.

42 Paralelamente al anuncio de Trump de implementar técnicas de geoingeniería a partir de 2018, se comunicó 
Se cierne sobre la humanidad un peligro real a causa del cambio climático y de las consecuencias de las medidas que se tomen para remediarlo. Este es un claro mensaje de determinación mundial: irreversibilidad con plena vigencia y sentido para ordenar la legislación vinculada al cambio climático de forma transparente y efectiva al servicio de la humanidad.

En cuanto a la regulación europea, se deben tener en cuenta por un lado la estrategía europea para el cambio climático en relación con la Directiva 2001/42/CE ${ }^{43}$ y la Decisión 1386/2013. La Directiva acentúa la necesidad de integrar, a través de los planes y programas ambientales, aquellos aspectos que potencien y garanticen el desarrollo sostenible. El objetivo primordial del artículo 1 es alcanzar un elevado nivel de protección ambiental a través de la evaluación a través de las repercusiones medioambientales de tales planes y programas. Contempla la información al ciudadano y la consulta como herramientas de retroalimentación, de acuerdo con su artículo 6, dando la posibilidad de expresar las opiniones, y siendo cada Estado Miembro quien determine los modos y condiciones de tal expresión.

Se presentan en el discurrir, ahora con carta de naturaleza, las mencionadas cuestiones relativas a la información y a la contaminación transfronteriza en las prácticas de geoingeniería para la manipulación del clima. En el espacio de la Unión Europea las normas marcan el camino a seguir, de forma que ha de ponerse en conocimiento de cualquier miembro afectado aquellas actividades que puedan resultar dañinas y que escapen del ámbito jurisdiccional donde se estén aplicando. En concreto, el Convenio de Aarhus se refiere al derecho de acceder a la información y participar en las decisiones adoptadas en materia de medio ambiente a particulares y asociaciones que los representan. Entre sus puntos clave destaca la garantía sobre el acceso del público a la información en materia de medio ambiente de que disponen las autoridades públicas, el favorecer la participación del público en la toma de decisiones y ampliar las condiciones de acceso a la justicia. Parte de la premisa de que una mayor sensibilización e implicación del público en las cuestiones medioambientales favorecerá su protección. Este también es el caso de la emisión de sustancias para la manipulación del clima. En este sentido su artículo 9 garantiza la puesta a disposición del público y resto de Estados Miembros del plan o programa en cuestión, una declaración resumida de la intencionalidad y las medidas de control. A la luz de las disposiciones que recoge la Directiva, se evidencia con más claridad si cabe, la necesidad de dotar de transparencia las eventuales

la firma, sólo un día antes, del documento ejecutivo que revocaba las medidas adoptadas por el Gobierno Obama para el cuidado del medio ambiente. No teniendo claro si permanecería en el Acuerdo de París. "Trump firma el Decreto que anula los Esfuerzos de Obama para frenar el Calentamiento Global" en La Vanguardia, 2017, 28 de marzo. Obtenido el 23 de mayo de 2017 en http://www.lavanguardia.com/internacional/20170328/421257607241/trump-obama- calentamiento-global.html .Interesa destacar aquí que sin embargo el pasado mayo la Cámara de Representantes de EEUU solicitó la adhesión al Acuerdo para limitar las emisiones de gases que provocan el cambio climático y el calentamiento global aprobada con 231 votos a favor y 190 en contra. En https://www.europapress.es/internacional/noticia-camara-representantes-pide-adhesion-eeuu-acuerdo-paris-contra-cambio-climatico-20190502205409.html. Acceso 5 agosto 2019.

43 Directiva 2001/42/CE, de 27 de junio de 2001, relativa a la evaluación de los efectos de determinados planes y programas en el medio ambiente. 
pruebas o prácticas de geoingeniería que se están llevando a cabo en Europa.

En cuanto a la Decisión 1386/2013 UE del Parlamento Europeo y del Consejo relativa al Programa General de la Unión en materia de Medio Ambiente hasta 2020 con el título "Vivir bien, respetando los límites de nuestro planeta" alerta sobre las tremendas pérdidas ocasionadas por el cambio climático, indicando tanto la complejidad del deterioro ambiental como la necesidad de atacar con medidas que de manera efectiva que se muestren válidas y oportunas. ${ }^{44}$ Así pues es tajante al indicar que

Para resolver algunos de estos complejos problemas es preciso explotar todo el potencial que ofrece la tecnológica medioambiental actual y garantizar el desarrollo constante y la adopción por la industria de las mejores técnicas disponibles y de las innovaciones que vayan surgiendo, así como una mayor aplicación de instrumentos de mercado. Es necesario, además, que se produzcan avances rápidos en campos prometedores de la ciencia y la tecnología. Esos avances podrían propiciarse impulsando la investigación y creando las condiciones necesarias para atraer inversiones privadas en ese sentido. Por otra parte, existe la necesidad de conocer mejor los riesgos potenciales para el medio ambiente y la salud humana que plantean las nuevas tecnologías, y de evaluar y gestionarse mejor dichas tecnologías. Esta es una condición sine qua non para que la población acepte las nuevas tecnologías y para que la Unión pueda identificar los riesgos potenciales asociados a los avances tecnológicos y actuar en consecuencia de una manera eficaz y oportuna. Las innovaciones tecnológicas importantes deben ir acompañadas de diálogos públicos y procesos participativos (DECISIÓN 1386 DEL PARLAMENTO EUROPEO, 2013, p. 13.)

Desde el análisis realizado a lo largo de las diferentes realidades normativas por las que hemos transitado, es en esta Decisión donde se reconoce claramente la importancia de conocer y controlar los riesgos que emanen de las prácticas utilizadas para reducir los efectos negativos sobre el medio. Ciertamente si se pretende la participación y lo que es más significativo, la aceptación de la ciudadanía en los avances tecnológicos que se van desarrollando para luchar contra el Cambio Climático, no podemos dejar de plantear la necesidad de que efectivamente se creen espacios por los que la información circule en doble vía (entre la Administración y los administrados), y no quede restringida al campo de la pura teoría. La ciudadanía tiene derecho a saber qué se está realizando y cuáles son sus consecuencias. La investigación sólo podrá ser impulsada si se cuenta con el consentimiento común, la participación en los foros de debate que será necesario abrir a partir de las disposiciones que esta Decisión tan oportunamente estipula. ${ }^{45}$

En España, la Constitución promulga en el art. 45 el derecho de todo ciudadano a disfrutar de un medio ambiente sano que sirva al desarrollo de la persona y la obligación de

44 VII PMA Programa General de Acción de la Unión en materia de Medio Ambiente hasta 2020 establece como segundo ámbito de acción entre otras medidas "la plena aplicación del paquete de medidas sobre clima y ener-gía para alcanzar las metas «20-20-20» y un acuerdo sobre los siguientes pasos que debe dar la política climática más allá de 2020 online en https://ec.europa.eu/environment/ pubs/pdf/factsheets/7eap/es.pdf. Acceso en: 28 noviembre 2018.

45 Informe de la The Royal Society, Geoengineering the Climate. Science, governance and uncertainty.. ob. cit, p. 51. 
conservarlo. De la premisa constitucional se pasa a un gran abanico de leyes de protección recogidas en el Código de Atmosfera y Cambio Climático, ${ }^{46}$ de las cuales tomaremos como referencia únicamente la Ley de Aguas, cuyo objeto de regulación como indica su primer artículo, es el dominio público hidráulico, el uso del agua, y las competencias atribuidas al Estado según el artículo 149 de la Constitución. Dentro de las cuales resulta sorprendente ver en el artículo 3, que está la modificación de la fase atmosférica del ciclo hidrológico de manera artificial. Esta referencia pone de manifiesto claramente las posibilidades de modificación de precipitaciones y por tanto la climatología en España. ${ }^{47}$

Respecto al mencionado derecho de información que estamos tratando en relación con la manipulación climática la Ley española 34/200748 refleja el compromiso que adquiere la Administración de cara a la ciudadanía, organizaciones ecologistas, empresariales, etc. respecto a la calidad del aire, los indicadores ambientales elaborados por el Ministerio de Medio Ambiente, así como de los planes y programas para proteger la atmósfera y minimizar el impacto negativo de la contaminación. ${ }^{49}$

\section{FUNDAMENTOS DEL DERECHO AL CLIMA: AXIOLOGIA CLIMÁTICA, Y OBJETIVO 13 DEL DESARROLLO SOSTENIBLE, LA ACCIÓN POR EL CLIMA}

Ciertamente la necesidad de paliar los desfases en las temperaturas terrestres, se impone de modo perentorio, reclamando del ser humano una acción contundente por el Clima, dirigida a devolver al medio el equilibrio natural. La modificación climática mediante técnicas de geoingeniería, abre la caja de Pandora, las dudas que plantea en el orden jurídico, no son asunto baladí, no deben quedar a la ligereza del soft law que pese a sus esfuerzos no parece efectivo en lo que se refiere al cambio climático.

Al servicio del poder, económico, social y geopolítico se intuye que una élite está jugando con los patrones climáticos para cumplir con sus intereses, la gravedad de esta situación exige una respuesta jurídica en defensa del camino recorrido por la humanidad para ser considerados todos los hombre iguales en derechos, para aceptar las limitaciones de libertad de las normas por estar dentro del contrato social y democrático, para defender derechos que tenemos por el hecho de ser personas y cumplir con la obligación de cuidar de nuestra hermana-madre Tierra.

Encontramos una respuesta jurídica a estos graves asuntos, como suele ser habitual, en la

46 Véase https://www.boe.es/biblioteca_juridica/codigos/codigo.php?id=123_Codigo_de_Atmosfera_y_ Cambio_Climatico\&modo $=1$.

47 Real Decreto Legislativo 1/2001, de 20 de julio, por el que se aprueba el Texto Refundido de la Ley de Aguas.

48 Ley 34/2007, de 15 de noviembre, de calidad del aire y protección de la atmósfera.

49 La Ley 27/2006, transpone el contenido del Convenio de Aarhus, relativo al derecho de acceso a la información, participación y justicia en caso de ser ambos denegados. https:/eur-lex.europa.eu/legal-content/ES/ TXT/?uri=LEGISSUM\%3Al28056. 
ingeniería jurídica a partir de los fundamentos del Derecho, especialmente en su dimensión axiológica. Así, aparecen en el escenario internacional demandas que tienen por objeto la satisfacción de los valores ecológicos vinculados al derecho al Clima como la huelga escolar en las puertas del Parlamento sueco que Greta THUNBERG con 16 años, comenzó después, de la Conferencia de Katowice. Su iniciativa de los Fridays for Future se ha covertido en poco tiempo en un movimiento mundial denunciando la inacción gubernamental frente al cambio climático. ${ }^{50}$

En el mismo sentido, las poblaciones indígenas vienen reclamando desde lejos el Derecho humano al medio ambiente. Principalmente desde la exigencia al derecho a la tierra en la que se asientan que ha marcado sin duda el precedente más cercano en la argumentación jurídica para su configuración y protección. Como ya he indicado

\begin{abstract}
cobra aquí importancia el mecanismo de denuncia que marca el Protocolo facultativo del pacto de Derechos Económicos Sociales y Culturales... por el que a través de denuncias individuales permite proteger a las personas o grupos que afirman que sus derechos en virtud del Pacto han sido violados... En este espacio, además de los compromisos de respeto pactados por la comunidad internacional, se definen procedimientos útiles para su defensa como el procedimiento confidencial de la Resolución 1503 de la ECOSOC de $1970^{51}$ por el que la Comisión debe actuar cuando recibe algún informe firmado que muestre violaciones graves y continuadas de los Derechos Humanos (MENDEZ ROCASOLANO, 2015, p. 157).
\end{abstract}

Sin embargo fue en 2005, ante una petición de los inuits a la Comisión Interamericana de Derechos Humanos cuando se abrió por primera vez de forma explícita la posibilidad de comprometer la responsabilidad gubernamental en la reducción de las emisiones de gases de efecto invernadero con posibles violaciones de los derechos humanos. ${ }^{52}$ Se vinculaba a derechos consagrados en el ámbito internacional y constitucional, como el derecho a la vida, a la salud, a la integridad física entre otros, con la protección frente a daños asociados con el cambio climático y el medio ambiente.

El pionero caso Leghari_en Pakistán y más recientemente el de la Fundación Urgenda versus el gobierno de Holanda han contribuido a allanar el camino de su reconocimiento. En el primer caso, el Tribunal pakistaní puso de manifiesto que la inactividad gubernamental ante el cambio climático violaba los derechos fundamentales. Así declaró: ${ }^{53}$

El cambio climático es un desafío que define nuestros tiempos y ha provocado alteraciones dramáticas en el sistema climático de nuestro planeta. Para Pakis-

50 Vease para una mayor información https://www.fridaysforfuture.org/. Acceso el 29 de julio 2019.

51 Para un estudio detenido del procedimiento véase Mendez Rocasolano (2013, p. 51-93).

52 Las regiones del Ártico de Estados Unidos y Canadá reclamaron contra Estados Unidos sus derechos humanos vinculados al medio ambiente. En primer lugar por ser el principal emisor con aproximadamente el 25\% del total mundial de los gases efecto invernadero, también su negativa a reducirlas. Finalmente en 2006, la Comisión inadmitió la reclamación basándose en el artículo 26 del Reglamento de la Comisión e indicando que la información proporcionada no permitía determinar si los hechos alegados caracterizan una violación de los derechos protegidos por la Declaración Americana. Para un conocimiento más extenso se recomienda la consulta de Torrecuadrada Garcia-Lozano y Fernandez Egea (2015).

53 En https://www.openglobalrights.org /litigating-the-right-to -a-sustainable-climate-system/?lang =Spanishpara ver el fallo https://elaw.org/system/files/pk leghari. 090415_0.pdf. 
tán, estas variaciones climáticas han provocado principalmente grandes inundaciones y sequías, lo que ha suscitado graves preocupaciones con respecto al agua y la seguridad alimentaria. En un plano legal y constitucional, esto es un llamado a la protección de los derechos fundamentales de los ciudadanos de Pakistán, en particular, de los segmentos vulnerables y débiles de la sociedad que no pueden acudir a este Tribunal (ORDER SHEETIN THE LAHORE HIGH COURT LAHORE JUDICIAL DEPARTMENT, 2015, online).

En el caso Urgenda,el Tribunal de Distrito de La Haya sostuvo que el gobierno holandés violó el deber de protección ciudadana por mantener objetivos de reducción de emisiones muy por debajo de los exigidos internacionalmente. Fue en la apelación cuando el Tribunal ${ }^{54}$ se refirió a los Derechos Humanos que según el Convenio Europeo imponen al gobierno holandés el deber de proteger contra la "amenaza real de un cambio climático peligroso, que da lugar a un grave riesgo de que la generación actual de ciudadanos se enfrente a la pérdida de vidas humanas o a una perturbación de la vida familiar." (ECLI; GHDHA, 2018, online). Así se impuso la reducción de las emisiones de gases con efecto invernadero holandesas en al menos un 25\% por debajo de las de 1990 antes de 2020 por los daños climáticos.

En el mismo sentido ha sido el reconocimiento de la Corte Interamericana de Derechos Humanos que respondiendo a una opinión consultiva en noviembre de 2017 mantuvo el derecho a un medio ambiente sano como un derecho humano que podría verse afectado por la degradación ambiental y el cambio climático. ${ }^{55}$

Estos no son casos aislados, si no que ven completados con distintas demandas en diferentes países que mantienen las mismas pretensiones. Así el caso Earthlife Africa Johannesburg v. Minister of Environmental Affairs and others en Sudáfrica, ${ }^{56}$ las demandas de los Saamis en el norte de Europa y el caso Greenpeace Southeastasia (Filipinas) versus Chevron (Us), Exxon Mobil(Us),Bp (Uk), Royal Dutch Shel, ${ }^{57}$ y el Environnement Jeunesse v. Canada entre otros. Dentro de ellos destaca la reciente jurisprudencia colombiana ${ }^{58}$ que sienta un precedente en el derecho y las acciones contra el cambio climático. En el caso Lozano Barragan, veinticinco jóvenes han demandado su derecho a un medio ambiente sano y sostenible frente al gobierno, obteniendo el fallo favorable de su Tribunal Supremo. La sentencia establece que el gobierno es responsable de dificultar el ejercicio de los derechos fundamentales al agua, a respirar aire puro y a disfrutar de un ambiente sano que está enfermando a los colombianos, aumenta la carencia de agua dulce y disminuye las expectativas de vida digna. Como

54 Vease https://www.urgenda.nl/wp-content/uploads/ECLI_NL_GHDHA_2018_2610. Pdf. Para ver el desarrollo interesa la consulta de Peel y Osofsky (2019, p. 311-336).

55 Véase http://www.corteidh.or.cr/docs/opiniones/seriea_23_esp.pdf.

56 Véase Earthlife Africa Johannesburg v. Minister of Environmental Affairs and others, Case no. 65662/16 (2017) https://elaw.org/SA_EarthlifeAfrica_MinEnviro_Mar2017.

57 Véase https://www.climateliabilitynews.org/2018/09/20/philippines-human-rights-climate-hearing/.

58 Véase https://www.dejusticia.org/wp-content/uploads/2018/01/Fallo-Corte-Suprema-de-Justicia-Litigio-Cambio-Clim\%C3\%A1tico.pdf?x54537. 
sostuvo Rodríguez (abogado de la demante) ${ }^{59}$

El fallo es un paso fundamental en la dirección que ya venían dando otras cortes alrededor del mundo, que han ordenado a los gobiernos cumplir y aumentar sus compromisos contra el calentamiento global. En este caso, además de recoger el consenso científico sobre la importancia de los bosques en la mitigación del cambio climático, el fallo avanza al declarar la Amazonía como sujeto de derechos, lo que permite proteger ese ecosistema esencial para Colombia y la humanidad (GUZMÁN, 2018, online).

Igualmente, mientras que en este tórrido verano del 2019 arde la amazonía Brasileira, ${ }^{60}$ nos detendremos en la demanda de la asociación Our Children en la que Juliana en representación de los jóvenes entre doce y veintidos años, en el año dos mil quince presentó una demanda contra el Gobierno de los EEUU. En ella aparece la expresión concreta de los valores de protección y defensa del clima, cobrando sentido como en los casos mencionados la dinamogénesis de los valores y su expresión concreta que posibilita mantener coherentemente la relación jurídica básica constitutiva del derecho que nos ocupa.

A través de esta demanda norteamericana se continua poniendo de manifiesto el ímpetu de las nuevas generaciones y así en el caso Julianna vs. Estados Unidos, se reclama la protección judicial del Clima, vinculando el derecho constitucional a la vida, la libertad y la propiedad, exigiendo al gobiernos de los EEUU responsabilidad por no tomar las medidas oportunas para evitar catástrofes climáticas. ${ }^{61}$ La pretensión planteada, que se dirimirá en el juzgado del distrito de Eugenio en Oregón, pone en jaque al gobierno federal norteamericano al pretender la implementación de un programa cuyo fin sea reducir drásticamente el nivel de partículas de dióxido de carbono en la atmósfera, situándolas por debajo de 350 partes por millón frente a las 405 partes por millón de media en 2017 que como hemos indicado suponen imprevisibles efectos para el Clima del Planeta. De hecho, recuérdese que se tiene esta medida como punto de no retorno. La trascendencia de este procedimiento radica en representar un antes y un después en la consideración de la protección medioambiental vinculada a los derechos humanos en suelo norteamericano. El fundamento jurídico que inspira este proceso es la institución del fideicomiso público propuesto por Mary Wood. La profesora de la universidad de Oregón, reconocida experta en derecho ambiental, comprendió que ésta era la vía para poder plantear la defensa pues el fideicomiso público, ${ }^{62}$ asume que...

59 Véase https://www.dejusticia.org/en-fallo-historico-corte-suprema-concede-tutela-de-cambio-climatico-y-generaciones-futuras/.

60 https://www.elperiodico.com/es/internacional/20190822/por-que-se-quema-el-amazonas-7601767.

61 Visto en Microjuris.com en https://aldia.microjuris.com/2018/11/24/supremo-federal-permite-historica-demanda-sobre-cambio-climatico/ el 19 de julio de 2019.

62 A la conferencia ofrecida por la académica Wood en el año 2010 en la cual planteó esta cuestión, asistió como público Julia OLSON, prestigiosa abogada, que comprendió la idoneidad de este planteamiento, creyendo en la posibilidad de sacarlo para adelante. Así, creó la citada asociación Our Childrren Trust, comenzando esta apasionante andadura en defensa del derecho a la protección del sistema climático, reclamando la denominada justicia climática. Visto en https:/elpais.com/sociedad/2018/10/21/ actualidad/1540142696_429722.html el 19 de julio de 2019. 
el público es el propietario de los recursos naturales, no es propiedad privada, pero sí propiedad pública, y el Gobierno, por ser la institución que perdura, debe gestionar esos recursos como fideicomisario para los ciudadanos presentes y las generaciones futuras. Si se prueba que el gobierno con sus acciones ha alterado sustancialmente la atmósfera y el sistema climático, habría violado ese fideicomiso público que debe a los ciudadanos (WOOD, 2010 apud GUIMÓN, 2018, online).

Por su parte, el departamento de justicia defiende que no existe el derecho a un sistema climático capaz de sostener la vida humana y que la Quinta Enmienda a la cual se acogen los demandantes, en la que se recoge el derecho a la vida la libertad y la propiedad, no lo expresa. Toca esperar la sentencia, en cualquier caso, el camino de este procedimiento abre nuevas posibilidades que tendrán que explorarse en los años venideros en Estados Unidos, lo que resulta fundamental teniendo en cuenta que es uno de los países con más emisiones de gases efecto invernadero, lo que nos efecta a todos...

Volviendo una mirada al panorama regulador del Clima y sus consecuencias, desde la firma del acuerdo de París celebrado en diciembre de 2015, se viene reconociendo tal vínculo. Y es en base a este reconocimiento por el que se está planteando la defensa a un clima adecuado, a un medio ambiente saludable, sostenible y protegido. En la actualidad, cuando la protección del medio ambiente, se sitúa por primera vez en posición preeminente, parece que toca al operador jurídico platear hipótesis, posibilidades y respuestas.

El quid de la cuestión se encuentra en la vinculación con los derechos que asisten al ser humano, cobrando, el clima, la relevancia necesaria para obtener la imprescindible atención judicial que satisfaga las pretensiones reales del derecho a un sistema climático que sea protegido por los Gobiernos de cada país, en cada rincón del mundo, como eje principal de una política real de acción protectora.

En sintonía con el Objetivo de Desarrollo Sostenible 13, del Programa de Naciones Unidas, la acción por el Clima, se establece la necesidad de apoyar a las regiones más vulnerables, establecer medidas de reducción de riesgos de desastres en las políticas y estrategias nacionales y establecer, mediante la voluntad política, actos efectivos para lograr una protección ambiental real e inmediata. Por supuesto en el medio y largo plazo también urge la protección ambiental. La clave para que la voluntad política sea ciertamente efectiva y con un compromiso legal de cumplimiento, es como estamos indicando que la base de la estrategia quede vinculada a los Derechos Humanos, lo que puede realizarse además de forma específica con el derecho al agua incorporado en la lista de derechos humanos desde el año 2010. Esta posibilidad ha sido reconocida por el Consejo de Derechos Humanos, estableciendo para ello unos ejes fundamentales de acción que permitan, en base al respeto inexorable de los Derechos Humanos tres premisas. En primer lugar que las políticas y programas de los países estén basados en el cumplimiento de los Derechos Humanos. Además identificar a los derechohabientes y sus prerrogativas. Los titulares de deberes y obligaciones, a fin de diseñar los cauces exactos que permitan a unos el ejercicio de sus derechos y a otros, 
el cumplimiento de sus obligaciones. Y finalmente desarrollar una red de principios y una normativa derivada de los derechos humanos, ${ }^{63}$ que inspire eficazmente el proceso íntegro de la creación de tales políticas.

Se convierte en imperiosa la necesidad de que los Gobiernos se impliquen efectivamente en la creación de políticas protectoras del medio ambiente, del clima y en definitiva, del derecho a la vida de las personas y a su dignidad en relación con el medio. Es primordial una planificación vinculada constitucionalmente, que por encima de los intereses políticos y partidistas, obligue al exhaustivo cumplimiento de las políticas ambientales encaminadas a la protección de la vida, que emanando de la legislación fundamental, irradie a todos los estadios de la sociedad. De modo que las Instituciones, las empresas y los ciudadanos queden obligados por igual al cumplimiento de esta defensa, e igual modo, al ejercicio de los derechos a ella vinculados.

En esta tarea ayuda la fundamentación axiológica del derecho al Clima, que requiere en todo caso determinar la relación jurídica que ha de mediar entre los sujetos y el objeto de protección, definir los sujetos de la relación jurídica y fijar concretamente el objeto del derecho. Cualquier otra disquisición nos apartaría de la técnica jurídica situándonos en el ámbito de la opinión, la sociología y la política. Queda aquí planteado el reto de su configuración, a continuación se plantea únicamente la base sobre la que ha de levantarse la construcción apuntada, constituida por la dinamogénesis ${ }^{64}$ de los valores y el Derecho.

La diamogénesis de los valores, más conocida en tierras americanas ${ }^{65}$ como dinamogénesis de los derechos es un término compuesto por la expresión dinamo que supone movimiento y génesis o nacimiento, esta palabra que compuse en 1999 apunta al significado del proceso de creación, de reconocimiento de nuevos derechos que se inicia resaltando la importancia de los factores sociales como materia prima para el ámbito jurídico normativo e institucional. Tanto normas como instituciones son expresiones democráticas que se encargan de valores e intereses sentidos como valiosos socialmente. Elias Diaz lo expresaba magníficamente al indicar

la norma jurídica aparece en relación con una determinada realidad social- que le sirve de orden y sobre la cual, a su vez aquella opera -y en relación con una determinado sistema de valores- que orienta a esa normatividad y pretende, en casa caso servirle como fundamento y razón legitimadora (DÍAZ, 1982, p. 125 ).

Así pues, partimos de una explicación causal de los valores, ya que localizando la causa delimitamos qué efectos se pretenden, cuál es el objeto y la finalidad con la que se conciben. ${ }^{66}$

63 Informe 2018 de la Oficina del Alto Comisionado de las Naciones Unidas para los Derechos Humanos ACNUDH hace referencia a tal vinculación.

64 Con dinamogénesis de los valores y el derecho nos referimos al proceso continuado en el que los valores están inmersos y que puede resumirse en las siguientes etapas: a) conocimiento-descubrimento de los mismos por la sociedad; b) posterior adhesión social a los mismos; y la consecuencia inmediata: c) concreción de los valores a través del derecho en su producción normativa e institucional.

65 Vease Oliveira da Silveira y Mendez Rocasolano (2010).

66 En este punto es interesante la lectura de las páginas que tratan del origen de los valores y la política, la referencia que hace a Kant, el acercamiento a Max Scheller y la alusión a la filosofía del lenguaje moral en 
En este sentido, los valores ecológicos y de subsistencia vinculados al cambio climático serán igual que el todo al que pertenecen, anteriores a la existencia del derecho al clima, que en definitiva ha de ser expresión y concreción de aquellos. Cabe aquí hacer dos observaciones. En primer lugar, que los valores en la sociedad se manifiestan como cultura por lo que en este sentido la cultura sería la realización de los valores en la sociedad y además, que el Derecho es la concreción de los valores en el ámbito social. El Derecho, así entendido se manifiesta como expresión cultural, es el medio a través del cual se realiza la labor fundamentadora e inspiradora de derechos y obligaciones ${ }^{67} \mathrm{y}$ así es como se va trabando la formulación del derecho al Clima, de forma que cuando el Derecho regula la conducta de la comunidad humana reflejando a través de normas e instituciones el orden axiológico, aparece el deber ser valorativo (Geistensollen von Werten). Por ello, el Derecho tienen como bueno/a la conducta que se ajusta a los valores, incluso los proyecta de acuerdo a su deber ser y rechaza, penaliza, lo contrario a los valores o aquello que se opone al deber ser de los mismos.

Los valores son elementos prejurídicos y metajurídicos ya que condicionan y fundamentan al Derecho que es reflejo imperativo y poderoso de ese sentir axiológico. A través de la juridificación de los valores, estos que ya son, viven, saltan del plano ideal (sentimental) al real, porque pueden exigirse, garantizarse y protegerse.

De entre los llamados derechos de la cuarta generación se enuncia el de la ciudadanía a acceder a la información en materia medioambiental, y concretamente en aquellas actividades que causen un daño grave, nocivo o perdurable. Lo que se convierte en una exigencia para la manipulación climática a través de la geoingeniería. En este caso, el contenido básico de este nuevo derecho está siendo desconocido e infringido por las autoridades e instituciones del escenario nacional e internacional. Derivado del mismo y en aras a mantener la seguridad jurídica, con la intención de limitar el poder que la manipulación del clima representa, su regulación en términos accesibles se hace exigible para entender y preveer las consecuencias y daños que pudieran originarse. Aparece aquí la exigencia democrática de la expresión de la voluntad de la ciudadanía en las normas, engañar, confundir u ocultar información corrompe la relación que media entre la norma y la realidad. Es preciso un ajuste de ambas variables, de modo inequívoco y solvente para contar con la confianza en las Instituciones, como garantes de la plena satisfacción del Derecho y de los Derechos que corresponden a los ciudadanos.

El acceso a la información, participación de la ciudadanía en la toma de decisiones y acceso a la justicia en materia de medio ambiente se regula en el Convenio de Aarhus planteándose como premisas indiscutibles para las Administraciones Públicas.

Esta visión del Derecho como medio que reconoce valores sentidos como valiosos en la sociedad que impulsa la configuración de derechos, en el caso del derecho al Clima cum-

Cervantes Jáuregui (1991, p. 205-226).

67 En el mismo sentido se manifiesta Radbruch al decir que "el concepto de Derecho es un concepto de una realidad referida a valores, una realidad cuyo sentido consiste en estar al servicio de los valores. El Derecho es la realidad que tiene el sentido de servir al valor jurídico, a la idea de Derecho. El concepto de Derecho está pues, predibujado en la idea del Derecho" (RADBRUCH, 1933, p. 44). 
ple con la afirmación siguiente: la cultura actual contiene valores vinculados a la ecología y a la protección del Clima que son sentidos como tales por la sociedad conviertiéndose en valiosos, el Derecho ha de encargarse de protegerlos y garantizarlos dándoles contenido normalmente con la expresión de derecho de o derecho a el clima .

Si el sentimiento axiológico de la sociedad no tiene un reflejo dentro del Derecho podemos decir que ese Derecho queda obsoleto o no satisface los intereses que la sociedad exige, no cumple con su función. Cobran aquí sentido las palabras del Papa Francisco que actualiza la interpretación del concepto "cuidado de la tierra", a través del concepto de ecología integral incorporando la moral. A través de ella, como expresiónaxiológica se forjan en el ser humano los valores que lo caracterizan y los imprime a sus acciones. No importa la capacidad que se tenga o no de llevar a cabo determinadas medidas, sino la moralidad intrínseca a ellas. Ha de ser el Derecho la vía que ordene las actuaciones del hombre hacia la justicia al medio ambiente. ${ }^{68}$

Antes de implementar técnicas que a todas luces plantean inconvenientes, dudas razonables en cuanto su utilidad, peligrosidad y eficacia respecto a la manipulación climática, deberían llevarse a cabo aquellas que se saben ciertas, basadas en la reducción del consumo, la reutilización y el reciclaje, la implementación progresiva de la economía circular ${ }^{69}$ y la solidaridad en el primer mundo, el desarrollo consciente en el resto, aunque ello suponga un cambio en el modelo productivo mundial, ya no sirve "quien contamina paga". A la humanidad se le exige acción, en nuestro caso acción por el Clima y el Derecho tiene que enfrentar el reto del planteamiento de la humanidad como sujeto de nuevos derechos y obligaciones, si el derecho al medio ambiente adecuado para el desarrollo de la persona es el más evidente hoy, el derecho al Clima para la vida digna parece que es una de sus concreciones más imperativas.

\section{CONCLUSIONES}

Los orígenes de los métodos de control del clima, conocidos hoy día como técnicas de geoingeniería son una manifestación del control humano sobre el medio. Ceñidas en un

68 El Papa Francisco ha publicado la encíclica Laudato centrada en el cuidado de la "casa común", el desarrollo humano integral y la ética medioambiental La encíclica, que consta de 6 capítulos, 246 números y 200 páginas, incide insistentemente en la necesidad de crear un sistema normativo que ponga límites a la degradación de los ecosistemas y garantice su protección. Así indica "Las predicciones catastróficas ya no pueden ser miradas con desprecio e ironía. A las próximas generaciones podríamos dejarles demasiados escombros, desiertos y suciedad. El ritmo de consumo, desperdicio y de alteración del medio ambiente ha superado las posibilidades del planeta, de tal manera que el estilo de vida actual, por ser insostenible, sólo puede terminar en catástrofes, como de hecho ya está ocurriendo periódicamente en diversas regiones. La atenuación de los efectos del actual desequilibrio depende de lo que hagamos ahora mismo, sobre todo si pensamos en la responsabilidad que nos atribuirán los que deberán soportar las peores consecuencias" (FRANCISCO, 2015, p. 161).

69 Resulta interesante la lectura de Investing in Climate, Investing in Growth de la OECD 2017 donde pone de manifiesto estos extremos. 
principio a cuestiones de estrategia económica y dominio militar, no ha sido hasta un presente más o menos inmediato cuando se han mostrado como técnicas aplicables a la mitigación de los efectos del cambio climático, en la esfera de actuación civil.

Existen inconvenientes reales en la aplicación de las técnicas de geoingeniería, dado el nivel de incertidumbre que plantean sus consecuencias contaminantes, las repercusiones en los órdenes físico, químico, sanitario, moral, político, económico y legal siendo además que el nivel de previsión de sus efectos es escaso, no permitiendo una estimación de posibles soluciones al eventual fracaso de su aplicación.

Una aproximación a su regulación pone de manifiesto que el Derecho se ha ocupado de la cuestión de manera irregular, transversal e insuficientemente. La relativa novedad de la cuestión, así como su aspecto controvertido, apenas ha permitido que se establezca una transparencia legislativa al respecto de su regulación.

La legislación norteamericana ha sido pionera respecto a las técnicas de modificación del clima para usos pacíficos, ${ }^{70}$ admitiendo en la actualidad junto con otros países, a trámite una demanda que pretende satisfacer el posible derecho al Clima, utilizando la institución del fieicomiso público como posibilidad de exigir el derecho al clima vinculado al derecho a la vida.

Desde una postura equilibrada entre el desarrollo económico y la sostenibilidad se brinda a la humanidad un cambio de paradigma a través de las soluciones que aporta la economía circular donde conviven ecología y economía de una manera real, contundente y definitiva. El derecho es la herramienta a través de la cual se ha de cohesionar la regulación de estas técnicas y su potencial intención de llevar a cabo planes y programas de aplicación. A través del sistema jurídico se han de regular los aspectos que atañen a la investigación y práctica de las técnicas de geoingeniería para la manipulación del clima; la información, participación en las decisiones que conciernen al asunto en cuestión, así como la responsabilidad de los Gobiernos, organismos y entidades involucradas.

Se hace necesario abordar definitivamente desde una perspectiva jurídica la cuestión de las técnicas de geoingeniería, cubrir los vacíos legales, y establecer el marco normativo que proteja los derechos de la ciudadanía. Partiendo para ello, como bien indican los Informes del IPCC, es fundamental la colaboración y cooperación interestatal. En la protección del clima y el posible derecho que implica, la vinculación con los derechos humanos es la base para establecer una protección real y efectiva del posible derecho al clima con una concreción de la relación jurídica, el sujeto, y el objeto de este nuevo derecho que ha de estar fundamentado en el compromiso de los Estados y en el de las personas que los conforman.

El Derecho proporciona las herramientas a partir de la ingeniería jurídica para la defensa de los intereses del ser humano, como individuo y como especie, estableciéndose los parámetros que delimiten o prohíban, gestionen o regulen su uso o abuso. A partir de la axiología y de los valores sociales mediante la dinamogénesis de los derechos, es posible a

70 National Weather Modificaction Policy Act of 1976, Septiembre de 1976, EEUU. ob.cit. Cabe recordar que la Convención ENMOD regulaba las técnicas de modificación climática usadas con fines no pacíficos u hostiles. 
partir del derecho a la información en materia ambiental y a la concienciación ecológica y los valores de defensa del Clima plantearse el derecho a una climatología natural vinculada al medio ambiente adecuado para el desarrollo de la persona lo que implica directamente el derecho al clima. Así lo apuntan el Tratado de Paris y los objetivos del Desarrollo Sostenible de las Naciones Unidas, en concreto el 13, que establece una acción por el Clima.

\section{REFERENCIAS}

BELLVER CAPELLA, Vicente. Ecología: de las razones a los derechos. Granada: Ecorama, 1994. BYERS, Horace R. "History of Weather-modification." In: WILMOT, HESS N. Weather and Climate Modification. New York: John Wiley\&Sons, 1974.

CALLEJA, José. "Cenizas, cementos y hormigones con cenizas" Materiales de Construcción N.87. Madrid: Consejo Superior de Investigaciones Científicas, 1982.

CERVANTES JÁUREGUI, Luis. Los valores políticos (Reflexiones acerca del vínculo entre la ética y la política). Mexico: Benemerita Universidad Autónoma de Puebla; Dirección General de Fomento Editorial, 1991.

CLINGERMAN, Forrest; O'BRIEN, Kevin J. Theological and Ethical Perspectives on Climate Engineering: Calming the Storm. Lanham, MD: Lexington Books, 2016.

DÍAZ, Elias. Sociología y filosofía del derecho. Madrid: Taurus, 1982.

FARMER, Thomas G.; COOK John. Climate Change Science: A Modern Synthesis: Volume 1.The Physical Climate. Dordecht: Springer Science \& Business Media, 2013.

FERRAJOLI, Luigi. Derecho y garantías. Madrid: Trotta, 1999.

FOUCAULT, Michel. Microfísica do Poder. Tradução Roberto Machado. Rio de Janeiro: Graal, 1979.

FRANCISCUS Papa. Encíclica Laudato si, mi Signore”, sanctus Franciscus Assisiensis cantabat. Vaticano: Librería Editrice Vaticana, 2015.

GUIMÓN, Pablo. 21 jóvenes sientan en el banquillo a EEUU por el cambio climático. El País, 21 oct. 2018. Disponible en: https://elpais.com/sociedad/2018/10/21/actualidad/1540142696_429722.html. Acceso en: 7 agosto 2016.

GÚZMAN, Diego. En fallo histórico Corte Suprema concede tutela de cambio climático y generaciones futuras. Dejusticia, 5 abr. 2018. Disponible en: https:/www.dejusticia.org/en-fallo-historico-corte-suprema-concede-tutela-de-cambio-climatico-y-generaciones-futuras/. Acceso en: 7 agosto 2016.

MARTIN MATEO, Ramón. Tratado de Derecho Ambiental. Madrid: Trivium SA, 1991. v. 1. 
MENDEZ ROCASOLANO, María. Cultural and Smart City: Torre-Pacheco. Madrid: Dykinson, 2017.

MENDEZ ROCASOLANO, María. Perspectivas y perfiles de la cultura y el pacto de los derechos económicos, sociales y culturales a la luz de la fe y la justicia. Prisma Jurídico 12, Sao Paulo, v. 12, n. 1, p. 51-93, 2013.

MÉNDEZ ROCASOLANO, María. Ambiente y Derecho Ambiental Concepto y Fuentes. Madrid: Rodela, 2005.

MEYER, William B. The Life and Times of US Weather: What Can We Do About it?"American Heritage 37, 1986.

MORENO, N. et al. "Phico-chemical characteristis of european pulverized coal combustion fly ashes. Fuel 84, v. 84, n. 2005. Universidad de Dundee, Escocia. Disponible en: http :// www.sciencedirect.com/science/article/pii/S0016236104003394. Acceso en: 7 agosto 2016. MURPHY, Michael J. (Director). Why in the World are they Spraying? EEUU 2013. Disponible en: https://www.youtube.com $/$ watch? $\mathrm{v}=7$ swthngNxQg. Acceso en: 15 agosto 2016.

NACIONES UNIDAS. Convención Marco de la Naciones Unidas Sobre el Cambio Climático. Nueva York, 1992. Disponible en: https://unfccc.int/resource/docs/convkp/convsp. pdf. Acceso en: 15 agosto 2016.

OLIVEIRA DA SILVEIRA, Vladmir; MENDEZ ROCASOLANO, María. Direitos Humanos: conceito, significados e funções. Sao Paulo: Saraiva, 2010.

PEEL, J.; OSOFSKY, H. International Judicial Practice on the Environment: Questions of Legitimacy (Studies on International Courts and Tribunals. Cambridge: Cambridge University Press, 2019.

PERLINGIERI, I. S. Las pruebas de que los chemtrails y la geoingeniería constituyen el mayor crimen de la Historia. 2013. Disponible en: http://recuperandoelcielo.es/wp-content/ uploads/2017/04/12-Estudio-El-mayor-crimen-de-la-historia-Sandra-Perlingieri.pdf. Acceso en: 6 mar. 2016.

PUY, Francisco. Derechos humanos. Derechos económicos,sociales y culturales. Santiago de Compostela: Paredes, 1983. v. 1.

RADBRUCH, Gustav. Filosofía del Derecho. Trad. José Medina Echevarría. Madrid: Revista de Derecho Privado, 1933.

REALE, Miguel. Teoría tridimensional do direito. Sâo Paulo: Saravia, 1968.

RECASENS SICHES, Luis. Introducción al estudio del Derecho. 6. ed. Mexico: Porrua, 1981.

ROUSSEAU, Jean Jacques. Segundo discurso sobre la desigualdad entre los hombres. 
Madrid: Tecnos, 1987.

STOCKER, T. F. D. et al. (eds.). IPCC, 2013: Climate Change 2013: The Physical Science Basis. Contribution of Working Group I to the Fifth Assessment Report of the Intergovernmental Panel on Climate Change. Cambridge University Press, 2014. Disponible en: http://www.ipcc.ch/ report/ar5/wg1/. Acceso 5 julio 2019.

TAMZY, Col. et al. Owning the wheather in 2025. [S.l.: s.n.], 1996.

TERRA SOS-TENIBLE. La manipulación del clima: un arma geopolítica vigente que viola los derechos fundamentales. Petición al Congreso de los Diputados. Zamora, 1 de febrero de 2016. Disponible en: http://www.guardacielos.org/users/1/Documentacion/Peticion_Congreso_Diputados_Febrero_2016_WEB.pdf. Acceso en: 19 sept. 2016.

TORRECUADRADA GARCIA-LOZANO, Soledad; FERNANDEZ EGEA, Rosa María. Los desafíos ambientales de las poblaciones indígenas en el Ártico. Estud. int. (Santiago, en línea), v. 47, n. 182, p. 57-77, 2015. Disponible en: https://scielo.conicyt.cl/scielo. php?script $=$ sci_arttext\&pid=S0719-37692015000300003\&lng=es\&nrm=iso. Acceso en: 19 sept. 2016.

VON MOHL, Rudolph. Encyklopädie der Staatswissenschaften. Freiburg und Tübingen: [s.n.], 1872.

VVAA. Geoengineering the Climate. Science, governance and uncertainty. Londres: The Royal Society, 2009.

WIGINTON, Dane. Geoingeniería, ¿una propuesta peligrosa o una realidad letal?. 2012. Disponible en: http://www.guardacielos.org/users /1/Documentacion/Geoingenieria_una_ propuesta_peligrosa_o_una_realidad_letal_DW_1.pdf._Acceso en: 1 jun. 2017.

WIGINTON, Dane. El asalto de la modificación climática global causa caos climático y catástrofe medioambiental. Disponible en: http://www.guardacielos.org/users/1/Documentacion/El_asalto_de_la_modificacion_climatica_R.pdf. Acceso en: 11 mar. 2016.

La Spiaggia (Rena Majore) Cerdeña agosto 2019 